\title{
Education of the Young Child
}

\author{
By Willard C. Olson
}

$\mathrm{A}$ MERICAN society has the task of assimilating the largest crop of young children in the history of the Nation. The record production has been reflected also in the desires of young parents for assistance in the task of rearing children. The present climate of opinion favors early marriage and the quick assumption of parental duties. Thus there is an enhanced interest in child development among those who regard themselves as future parents or professional workers or those who find through the study of the child a means of understanding human nature in general and themselves in particular. While national statistics are not available, enrollments in child development courses at one institution observed by the writer increased sixfold between prewar years and 1948-49. Similar expansions are typical elsewhere.

The current crop of young children is encountering shortages in housing, schoolrooms, teachers, and professional services of other types. Thus many practical problems crowd in and press for immediate solutions. There is, however, a continual and persistent interest in knowing more about the longtime strategy in child rearing, and in ways of communicating what is now known so as effectively to influence the behavior of parents, teachers, and professional workers.

\section{The Child at Home}

As is to be expected, ancient problems come up with new emphases. What is the proper social relationship between parent and child in the interest of desirable personality development? Is it better to rear an infant according to a very definite, superimposed, orderly schedule which may require coercion and force for its establishment, or is it better to emphasize individual differences in needs among children and to adopt flexible schedules? The more permissive philosophy emphasizes warm, affectionate relationships between child and parent. It is observed that schedules become orderly in terms of the individual differences in need and rhythm of bodily processes that exist among children. In the evaluations thus far made, children seem happier when parents do not attempt to force accomplishments in eating, sleeping, elimination, and motor and social development in advance of the necessary maturity.

The modern trend in pediatrics is to give much recognition to the individuality of children and to give self-regulation in practical operations the high status it already holds as an explanation of balance in bodily processes as obtained in studies of physiology and chemistry. This point of view is supported also by the studies of child psychiatry which note the powerful impact of disturbed emotions on the normal course of development. The cultural anthropologist is also responsible for a series of studies describing the importance of child-rearing practices in primitive societies in determining the adult personality that is produced. Research in child psychology and development is emphasizing the totality of the growth of the child, and the inability of the organism to take on training by habit-conditioning techniques in advance of readiness in the sense of maturity. 
Young parents are eager to learn what is best and newest in the child development field, and have an unusually rich supply of publications about children to assist them. Some of these are in the class of "best sellers." 1 Interest in child study has been reflected in the establishment of study clubs of various types, with or without connection with facilities for the care and education of the young child.

\section{The Child in the Nursery SCHOOL ${ }^{2}$}

The daily routine of the nursery school is designed to meet the needs of children for physical health and growth, for learning to get along with other children and adults, and for the development of experiences of every type. A typical full day program combines active play, a lunch, and a rest period. At times nursery schools are thought of as substitutive for the deficiencies found in some homes in lack of space, lack of other play associates, and lack of opportunity for parental supervision.

Some suggestive studies of the growth of children in independence and selfhelp during the nursery period indicate that better results are achieved if, in addition to a program for children, plans for participation or education involving the parents are developed, so that children receive a more consistent treatment over a much longer period than that of their school attendance.

In the early development of nursery schools it was feared that they might become centers for the spread of contagion. The appraisals that have been

1 Benjamin Spock, The Pocket Book of Baby and Child Care, New York: Pocket Books, 1946.

2 For a more extended discussion with statistical data, see Mary D. Davis, Schools for Children Under Six, Bulletin, 1945, No. 5, Office of Education, Washington: Government Printing Office, 1947. made of well-run establishments demonstrate that this fear was unfounded. Nursery schools fit in with the child's desire for growth in independence and with the need for association with other children in the interest of socialization. Most children find much joy in the possibilities offered by a well-planned nursery school environment. Parents have found in nursery school facilities opportunities for keeping a family together, for the continuation of employment, for relief for limited living quarters, for growth in understanding of child behavior, and for improved conditions for the health and well-being of their children.

A major stimulus for the extension of preschool facilities occurred during the economic depression, when moneys were made available from Federal sources for the establishment of nursery schools for the children of needy families.

During World War II there was a luxuriant growth of nursery schools, with the major justification of increasing manpower by releasing parents for work in connection with the war effort. Professionally trained persons connected with these enterprises always held also to the objectives of assisting in the education of the parents and improving the experiences of the children. Nursery school facilities and enrollments dropped off following the close of the war. It appears that they did so, not because of a lack of continued interest and need, but rather because emergency sources of support disappeared, and other agencies were unable or unwilling to take over the responsibility. About 10 per cent of families have women as their sole support, and employment is often contingent upon some plan for the handling of the young child. The individual methods worked out are often quite detrimental to the health and well-being of children, and 
the headliness each day report the social cost.

Some programs have survived and thrived under joint sponsorship by parents, school systems, and community agencies. In other instances strong cooperative programs were set up with professional persons in charge but with participation by parents to reduce costs. In some instances nursery schools were established through various plans for special aid to veterans. During the past twenty-five years, the nursery schools connected with child development laboratories and institutions of higher learning have been swamped by applications for their services. There seems to be no question that a larger development of nursery schools would be welcomed by the public if a sound basis for their support could be found.

Nursery schools have started under many auspices. After a study of the problem, the Educational Policies Commission ${ }^{3}$ concluded that they would be best served by a downward extension of existing schools and correlation with the total program of public education, including adult and parent education. The desire for such extension meets current obstacles in insufficient funds to provide housing and teachers for those children for whom society has already assumed an organized responsibility. The history of education suggests that any need felt by a large number of persons in a community will eventually be met. Legislatures have met the interest in a downward extension in part by making it permissive to operate nursery schools. At times existing acts have been interpreted so as to give local school officials authority to offer a program. Frequently, however, the financial support is not provided commen-

${ }^{3}$ Educational Policies Commission, Educational Services for Young Children, Washington: National Education Association, 1945, $56 \mathrm{pp}$. surate with that for other ages and school units.

\section{The Child in the Modern School}

It is not surprising that the ferment which is affecting the rearing of the young infant and nursery school child is paralleled by similar advances in the education of the child during the customary school years. Slowly but surely, a philosophy of growth based upon a study of the whole child and of individual differences among children is superseding the traditionally organized school program in which the emphasis is on adjusting the child to the curriculum rather than on adjusting the curriculum to the child.

The schools of the present that reflect the past often ignore individual differences in the young child, and still make use of a common assignment with reading, recitation, or written work based upon it. Accompanying this activity is the naïve belief that some additional homework or perhaps some special help from the parents or the teacher will enable the child who is making little progress to master the work that the class is doing. The emphasis in such a room is on teaching the content for the grade. Under such a plan the child fails, and he is then required to repeat a grade in the hope that he will eventually master its content.

The modern school recognizes that children at a chronological age of six will vary in maturity from about four to eight years of age. By age twelve these variations in growth are often as wide as from eight to sixteen years. Under the guiding principles of growth, the teacher aspires to give each child success at his level of readiness. A child who is at the kindergarten level in the second grade is met with that expectancy-a child who is at the fourth-grade level is not hampered by some abstract notion of the nature of 
a second grade. The teacher also plans with children so as to develop some social cohesiveness through experiences shared by the total group. If this does not succeed for particular children, the child may be studied on an individual basis so as to reclassify him for a more comfortable "social fit." Modern schools, operating on a knowledge of the great differences among children, do not expect more than minor palliative results from the many proposals to solve educational problems by the grouping of pupils.

How is the teacher to be wise enough to adjust expectancy and experience to the varying needs of children? In an earlier paragraph the growth of the selfregulation theory in the nurture of the infant was mentioned. The educational world has long had a similar concept implicit in some of its theory. Selfselection methods and participation of the learner in the determination of curriculum content now have numerous explicit demonstrations at school-age levels. For example, when a group of children at about the age of seven are exposed to a supply of books of varying difficulty and interest levels, individual children will select from it according to their maturity in the total growth process. ${ }^{4}$ Thus modern educational methods are becoming more dynamic as greater wisdom is achieved.

\section{Reading IN The Modern School}

The above concepts are not entirely accepted in practice, and the nature of a desirable introduction to reading is currently one of the hottest controversies in the education of the young child. Many still believe that there is some refinement of method that will enable practically all children to read at about a mental age of six and one-half, or

4 Willard C. Olson, Child Development (Boston: D. C. Heath, 1949), pp. $340 \mathrm{ff}$. that can be applied to the so-called "nonreader" at ages eight and nine so as to start him on the process and bring him up to some maturity level as determined by his calendar and mental age.

Contrasted to this point of view is the one of growth which notes that achievement in reading is a reflection of readiness as determined by total maturation, that there are patterns for growth curves in reading that run in families, and that children of appropriate maturity learn reading in an environment that values it and plans for it with so much rapidity and spontaneity that the process can hardly be halted long enough to examine it. Supporting the growth point of view is the failure of many specific methods designed for remediation to hold up under controlled comparisons. This failure has led to a mental hygiene approach to reading failure, ${ }^{5}$ which, in one sense, is a compensation for failure to adopt a growth point of view from the beginning. It has been observed that slow readers regularly present more than their share of personality and behavior problems, in addition to observable evidences of slow growth such as prematurity, undescended testes, and delays in motor skill and in traits such as dentition, strength, size, and skeletal ossification.

It has been observed in psychosomatic studies that children who receive an emotional shock of ten develop symptoms associated with their developmental state at the time. Thus a child who has an emotional episode at the time of a major shift (newer techniques advise gradualness) from liquid to solid food may persist in rejecting solid food and insist on mushy foods for several years.

5 See, for example, Virginia M. Axline, "Nondirective Therapy for Poor Readers," Journal of Consulting Psychology, Vol. 11 (1947), pp. 61-69. 
Similarly, the hypothesis may be held tentatively on the basis of clinical studies that a child who receives frustration and failure in his first contact with reading may thereafter reject and avoid the experience in spite of subsequent readiness. Thus the period of initial delay in learning may be unduly prolonged and may extend even into the teens.

Many modern teachers have achieved an understanding of growth as applied to achievement in the young child. Some parents, with the sincerest of motives, remain their child's worst enemy in this respect. Misunderstandings in these matters may threaten the security of the child at school, in the neighborhood, and in the home. ${ }^{.}$Modern educational practices attempt to reach the home with the latest evidence, with reassurance, and with techniques such as parent conferences, rather than with the obsolete science and practice involved in formal report cards.

\section{Programs in Human Relations}

The education of young children is currently reflecting one of the major problems of our time-human relationships. It has been demonstrated that children learn their responses. Simply listening to and reading about desirable attitudes and techniques means that the child is learning verbal responses, but is not necessarily learning how to do it. Modern ideas about the curriculum introduce a high degree of child participation in the choice of experiences and in the development of the plans which are to be followed. In interactive planning groups, children may accomplish many social learnings. In the evaluations that have been made of modern and traditional schools, it is noteworthy that

\footnotetext{
- Mary I. Preston, "Reading Failure and the Child's Security," American Journal of Orthopsychiatry, Vol. 10 (1940), pp. 239-52.
}

the differences in those areas of information and skill that are present in both are negligible for practical purposes. It is in initiative, invention, amount of production, zest in learning, and breadth that the modern school wins the laurels.

One of the most popular techniques for the study of social relations among children is the sociometric test. Through judicious questioning or observation, children are located who are unhappy or withdrawn from the group or who may be fighting against their surroundings because they are ignored or rejected by their associates. By appropriate statistical and graphical techniques it is possible to detect forces that are producing cleavage and to introduce factors that may be productive of an improvement of human relations.

Such studies make it clear that some of the forces reside within the child rather than in the structure of the group. Thus it becomes essential also to study and treat the affective and emotional life of the child.

\section{The Affective Life of the Chitd}

The self-regulating tendencies in the human body are based in part on the person's awareness of his bodily state. When equilibrium is destroyed, a child will engage in behavior designed to restore it. The most common and easily observed examples are hunger and thirst as a recognition of a need for food and water. Similarly, a child has a need to be active, and restriction of movement by an adult is fought by the child unless it coincides with the alternating need for rest. So-called basic needs are commonly satisfied through a social relationship, and thus the child quickly attains a superstructure of derived needs. The quality called security may be thought of as a harmony between internal needs and the social availability of the means for their satisfaction. 
Current investigations and clinical studies demonstrate that affective factors must be taken into account for best results at home and school. On the constructive and preventive side, the modern school gives a greater recognition to physical needs and provides broader curriculum opportunities so that all children can find something within it in which they can be interested and successful. By the abolition of failure techniques and the adoption of a growth philosophy, more children are kept in school for longer periods of time with happier experiences and attitudes.

The attainment and maintenance of a desirable affective state is a difficult matter for many children, and the complete explanation of emotional disturbance is still unavailable in terms of modern knowledge. Thus practically every classroom has in it one or more children with need for special remedial attention. A variety of interesting clinical tools have appeared under the general title of "projective tests." By reactions to pictures, by the exploitation of common materials such as clay, paint, and crayons, or by dramatic play with dolls and other equipment, the child tells the trained observer something about the matters that dominate his internal affective life. By encouraging a child to talk or act out his conflict, a therapeutic process is initiated. Thus the older ideas of discipline that operated on a superficial symptomatic level are being replaced or supplemented by plans for treatment by both individual and group processes.

As one observes that we already "know better than we do," and that there are many questions upon which we still lack definitive studies, one is impressed with the need for personnel and programs of investigation and demonstration.

\section{Training and Research in Child Development}

There is urgent need for a plan to prepare more workers for child study. The large increase in the number of children makes immediate demands of crisis proportions for additional nursery school, kindergarten, and elementary teachers. The expansion in enrollments in child development for general and professional education at the college level creates a serious personnel problem, since it requires many years to produce a competent investigator and instructor. In a number of professional fields where similar shortages have existed, moneys have been invested in various plans for scholarships and fellowships. Similar plans are needed for investigators and practitioners in the child study field.

There is a substantial time lag between the development of new concepts on the care and education of children and the application of these concepts in homes and schools. Programs of demonstration and research in communication are needed.

There is still a strong tendency for each research on children to be pursued from a highly specialized point of view. It is subsequently difficult to assimilate the specific findings into an operation that involves the entire child and his setting in the family and the community. Mistakes in application and interpretation are made even by highly trained persons, because they do not know the evidence from adjacent fields. Thus the writer once heard an eminent scientist blame lack of progress in reading in a child under his care on modern methods of teaching. He did not know that evidence from the study of the child as a whole makes reading a part of the total development of the individual and inseparable from it. $\mathrm{He}$ 
was asking for results in the field of reading that he could not produce in his own speciality for the same reasons. Thus it is entirely possible for parents and teachers to get conflicting information and advice from persons with presumably some right to speak. There is, therefore, much interest in broader programs of preparation for specialists, so that the pediatrician, the pedodontist, the child psychiatrist, the child psychologist, the nurse, the sociotherapist, and the teacher will have some verified concepts in common. Many researches on the development of children through time may also be pursued profitably by a team approach.

It seems probable that a much larger investment in fundamental research on childhood must be made by society before appreciable gains can be expected on pressing problems of delinquency, crime, physical health, and mental and emotional disturbances. It is symptomatic of a recognition of the above needs that a National Child Research
Act has been introduced in the Eightyfirst Congress with a broad mandate for training, research, and dissemination. The fate of the various bills with the same general purpose is not known at this writing.

\section{Summary}

The record crop of young children produces not only immediate crises in housing and professional personnel, but also a renewed enthusiasm and interest in both the long-time strategy and the day-to-day techniques for child rearing. At both home and school, the child encounters at the best a philosophy and practice which begins where he is and helps him to grow. Thus there is a new sensitivity to the social and emotional as well as the physical and intellectual needs of childhood. Augmented programs for the preparation of workers, for dissemination, and for research will be required to meet current problems in the education of the young child.

Willard C. Olson, Ph.D., Ann Arbor, Michigan, is professor of education and of psychology and director of research in child development at the University of Michigan. He was formerly on the staff of the University of Minnesota, and has also taught at the Ohio State University, the University of Chicago, and Columbia University. He is past president of the American Educational Research Association, and has served as secretary of the American Psychological Association, as vice president of the American OrthoPsychiatric Association, as consultant for various local, state, and Federal agencies, and as a member of the Social Science Research Council and of the National Research Council. He is the author of a large number of monographs and articles on scientific and professional problems, and of a recent textbook entitled Child Development. 